\title{
UNU-WIDER
}

WIDER Working Paper 2015/131

\section{Estimating multidimensional childhood poverty in the Democratic Republic of Congo, 2007 through 2013}

Kristi Mahrt, ${ }^{1}$ and Malokele Nanivazo ${ }^{2}$

December 2015 
Abstract: After years of economic decline, conflict, and instability, the Democratic Republic of Congo achieved rapid economic growth in the 2000s along with a reduction in rural consumption poverty. This paper evaluates the extent to which recent growth has been accompanied by improvements in multidimensional child welfare using a first-order dominance approach applied to Multiple Indicator Cluster Surveys and Demographic and Health Surveys. The authors explore the root of indeterminate outcomes in spatial analysis and evaluate the sensitivity of spatial and temporal outcomes to indicator choice. Though results do not indicate broad-based welfare advancement at the national, urban, or rural levels, they do suggest progress within a number of individual provinces.

Keywords: welfare, first-order dominance, Democratic Republic of Congo, multidimensional poverty, children

JEL classification: C81, I 32, J13

Tables: provided at the end of the paper.

${ }^{1}$ Independent contractor, corresponding author: kamahrt@gmail.com; ${ }^{2}$ University of Kansas.

This study has been prepared within the UNU-WIDER project 'Reconciling Africa's Growth, Poverty and Inequality Trends: Growth and Poverty Project (GAPP)'.

Copyright (C) UNU-WIDER 2015

ISSN 1798-7237 ISBN 978-92-9256-020-1

Typescript prepared by Lesley Ellen for UNU-WIDER.

UNU-WIDER gratefully acknowledges the financial contributions to the research programme from the governments of Denmark, Finland, Sweden, and the United Kingdom.

The World Institute for Development Economics Research (WIDER) was established by the United Nations University (UNU) as its first research and training centre and started work in Helsinki, Finland in 1985. The Institute undertakes applied research and policy analysis on structural changes affecting the developing and transitional economies, provides a forum for the advocacy of policies leading to robust, equitable and environmentally sustainable growth, and promotes capacity strengthening and training in the field of economic and social policy-making. Work is carried out by staff researchers and visiting scholars in Helsinki and through networks of collaborating scholars and institutions around the world.

UNU-WIDER, Katajanokanlaituri 6 B, 00160 Helsinki, Finland, wider.unu.edu

The views expressed in this publication are those of the author(s). Publication does not imply endorsement by the Institute or the United Nations University, nor by the programme/project sponsors, of any of the views expressed. 
The Democratic Republic of Congo (DRC) has endured decades of conflict, corruption, political and legal instability, poor infrastructure, and substandard macroeconomic policies. Given this volatile environment, it is not surprising that the DRC is among the poorest countries in the world based on both its gross domestic product (GPD) per capita and Human Development Index scores. Despite this unfavourable history, evidence suggests that the DRC has begun a path to recovery through a sustained average annual growth rate of 6 per cent since 2002 (World Bank 2014). Nonetheless, although estimated monetary poverty has fallen during this period of recovery from 71 per cent in 2005, nearly two-thirds of the population (63 per cent) remained poor in 2012 (UNDP 2014). Broader measures of welfare also continue to register low levels as evidenced by the DRC's likely failure to achieve any of the eight Millennium Development Goals (MDGs) (UNDP 2014).

This paper continues the work of Nanivazo and Mahrt (2016, forthcoming) in seeking to provide a broader understanding of non-monetary welfare in the DRC. For this purpose, Arndt et al.'s (2012) first-order dominance (FOD) approach is used to evaluate the distribution and evolution of multidimensional welfare of school-aged children in the 11 provinces of the DRC. The analysis spans the years 2007 to 2013, a period of ongoing localized conflict but overall increased political stability as well as strong economic growth. In addition to presenting FOD analysis, this paper delves into the possibility of FOD comparisons not determining dominance between two areas. Indeterminate outcomes may result from areas being very similar or very different across time and space. Understanding this distinction may be quite useful in evaluating FOD results.

The organization of this paper is as follows. Section 2 discusses indeterminate outcomes in FOD. Section 3 presents the data, discusses sampling issues, and defines the FOD indicators. Section 4 presents the FOD results and sensitivity analysis. Finally, Section 5 provides a concluding discussion.

\section{Indeterminate FOD outcomes}

The analysis presented in this paper employs the FOD approach to empirically evaluate the wellbeing of school-aged children in the 11 provinces and three aggregate areas (national, urban, and rural) in the DRC in 2001, 2007, 2010, and 2013. For detailed presentations of the FOD methodology see Arndt et al. 2012 or Arndt et al. 2013. In this section, we consider the possibility of FOD not establishing dominance between two populations over time or space. In general, indeterminate outcomes are likely when populations have very similar or very different welfare profiles; the latter is the focus of this discussion.

Given two populations A and B, the FOD criterion can be described as follows: population A first-order dominates population B if one can generate distribution B by transferring probability mass (i.e. moving individuals) from better to unambiguously worse outcomes within A. FOD dominance requires better welfare outcomes to be manifested throughout the population and across indicators. Indeterminate outcomes could stem from poor outcomes in a single indicator within a small subset of the population. Therefore, a dominant result provides a robust and broadbased indication of greater welfare through time or across space.

When welfare outcomes are not at all similar between areas or within the same area over time, FOD comparisons may result in indeterminate outcomes. We illustrate two scenarios involving two populations, $A$ and $B$. In both scenarios, 50 per cent of population A and 30 per cent of 
population B is not deprived in each indicator; however, the distribution of populations between welfare outcomes differs in each population and in each scenario. In Scenario 1, population A and $\mathrm{B}$ are similar in welfare patterns. However, fewer shares of population A fall into deprived welfare combinations and none of population $B$ is not deprived in any indicator. In this scenario, dominance of A over B is easily established. By transferring shares of population A from a strictly better outcome $(1,1,1)$ to strictly worse outcomes $(1,0,0),(0,1,0),(0,0,1)$, and $(0,0,0)$, the distribution of $\mathrm{B}$ is recreated.

Scenario 1: Population A dominates population B

\begin{tabular}{|c|c|c|c|c|c|}
\hline \multicolumn{6}{|c|}{ Population not deprived in each indicator (\%) } \\
\hline & Water & Sanitation & Shelter & & \\
\hline Urban & 50 & 50 & 50 & & \\
\hline Rural & 30 & 30 & 30 & & \\
\hline \multicolumn{6}{|c|}{ Population shares with each combination of welfare indicators (\%) } \\
\hline Water & Sanitation & Shelter & A & $\mathrm{B}$ & $A^{\prime}$ \\
\hline 0 & 0 & 0 & 0 & 10 & $7^{10}$ \\
\hline 0 & 0 & 1 & 25 & 30 & 30 \\
\hline 0 & 1 & 0 & 25 & 30 & 30 \\
\hline 1 & 0 & 0 & 25 & 30 & 30 \\
\hline 0 & 1 & 1 & 0 & 0 & 0 \\
\hline 1 & 0 & 1 & 0 & 0 & 0 \\
\hline 1 & 1 & 0 & 0 & 0 & 0 \\
\hline \multirow[t]{2}{*}{1} & 1 & 1 & 25 & 0 & 0 \\
\hline & Total & & 100 & 100 & 100 \\
\hline
\end{tabular}

Source: Authors' illustration.

Scenario 2 illustrates the possibility of an indeterminate outcome even when population A outperforms population B on average in every indicator (which precludes the possibility that B could dominate A). In this case, the distribution of population $A$ and $B$ falling into each combination of indicators is sufficiently different that population B's distribution cannot be created by moving shares of A to strictly worse outcomes. Specifically, because A's outcome $(0,1,0)$ is no better or worse than B's outcomes $(0,0,1)$ and $(1,0,0)$, B's distribution cannot be recreated. 
Scenario 2: Population A and population B are indeterminate

\begin{tabular}{|c|c|c|c|c|c|}
\hline \multicolumn{6}{|c|}{ Population not deprived in each indicator (\%) } \\
\hline & Water & Sanitation & \multicolumn{3}{|c|}{ Shelter } \\
\hline Urban & 50 & 50 & \multicolumn{3}{|l|}{50} \\
\hline Rural & 30 & 30 & \multicolumn{3}{|l|}{30} \\
\hline \multicolumn{6}{|c|}{ Population shares with each combination of welfare indicators (\%) } \\
\hline Water & Sanitation & Shelter & A & $\mathrm{B}$ & $A^{\prime}$ \\
\hline 0 & 0 & 0 & 0 & 10 & 10 \\
\hline 0 & 0 & 1 & 0 & $30 \ldots$ & 25 \\
\hline 0 & 1 & 0 & 50. & 30 & 40 \\
\hline 1 & 0 & 0 & 0 & 30. & 725 \\
\hline 0 & 1 & 1 & 0 & $\theta$ & 0 \\
\hline 1 & 0 & 1 & 50 & 0 & 0 \\
\hline 1 & 1 & 0 & 0 & 0 & 0 \\
\hline \multirow[t]{2}{*}{1} & 1 & 1 & 0 & 0 & 0 \\
\hline & & Total & 100 & 100 & 100 \\
\hline
\end{tabular}

Source: Authors' illustration.

From an analytical perspective, it would be useful to understand if indeterminate outcomes resulted from similarities or differences across time or space. While this distinction may not be immediately obvious, basic descriptive statistics may in some cases shed light on the inability of FOD to determine dominance. The following section evaluates descriptive statistics and Section 4 applies these observations to the FOD results.

\section{$3 \quad$ FOD indicators}

\subsection{Survey data}

The FOD indicators are drawn from the 2007 and 2013 DRC Demographic Health Surverys (DHS) and 2010 DRC Multiple Indicator Cluster Survey (MICS), tabulated by the Ministry of Planning and Macro International Inc. (2008), Ministry of Planning et al. (2014), and the National Institute of Statistics and UNICEF (2011), respectively. The surveys are nationally representative household surveys that follow a similar sampling scheme with stratification by provinces as well as cities, towns, and rural areas. Sample sizes increase over time with 8,886,11,393, and 18,171 households included in the 2007 DHS, the 2010 MICS, and the 2013 DHS, respectively. The sample of school-aged children used in this analysis is restricted to children aged 7-17 with nonmissing values for all indicators and the sample increases from 13,397 in 2007 to 17,351 in 2010 and 27,905 in 2013.

It is worth emphasizing that data collection is a challenging endeavour in DRC. Given its recent tumultuous history, institutional weaknesses, and the lack of trust of the population vis-à-vis agents of the government (enumerators), the scope for non-sample error is large. Even sample biases are difficult to control. The most recent census was collected more than 30 years ago, in 1984. All recent national surveys, including the DHS, the MICS, and the Enquête 1-2-3 (the basis of national consumption poverty estimates), base their sample frames on a combination of the 1984 census and administrative censuses. This is well short of ideal. Consequently, figures derived from the three surveys in focus here should be interpreted with a degree of caution. 
The lack of a proper sample frame becomes apparent in the fluctuation in the urban sample size from year to year. In the sample of all individuals, the urban sample fluctuates between 42.9, 30.3, and 34.5 per cent in 2007, 2010, and 2013. To reduce the influence of these ad hoc sample frame variations on outcomes, we reweight the sample in order to strike World Bank (2014) urban population share estimates of 38.5, 39.4, and 41.5 per cent in 2007, 2010, and 2013 respectively.

\subsection{Indicator definitions}

The FOD methodology is rooted in measuring welfare profiles of populations based on a set of binary indicators. Given the deep and extensive nature of poverty in the DRC, we define child poverty as a severe lack of access to basic needs. Gordon et al. (2003a, 2003b) developed a set of indicators, known as the 'Bristol Indicators'. Specifically, severe deprivations are defined as 'circumstances that are highly likely to have serious adverse consequences for the health, wellbeing, and development of children' (Gordon et al. 2003b: p5). Closely following the 'Bristol Indicators', Nanivazo and Mahrt (2016, forthcoming) define five deprivation indicators for children aged $7-17,{ }^{1}$ which are adopted in this analysis. Each indicator is defined according to a deprivation threshold such that children with outcomes better than the threshold are considered not deprived. Deprivation thresholds are described below:

1. Water deprivation: Children with only access to surface water for drinking or for whom the nearest source of water is more than a 30-minute walking distance from their dwellings.

2. Sanitation deprivation: Children with no access to any kind of latrines or toilets.

3. Shelter deprivation: Children living in dwellings with five or more people per room or with no flooring material (e.g. a mud floor).

4. Health deprivation: Children who did not sleep under a bed net the previous night. ${ }^{2}$

5. Information deprivation: Children who belong to a household where there is no access to a television, radio, or phone. ${ }^{3}$

6. Education deprivation: Children who have never been to at least primary school or are not currently attending school.

Table 1 reports the percentage of school-aged children not deprived in water, sanitation, shelter, health, information, and education by area and years. Though the indicators provide mixed evidence of advancement and stagnation, the picture is typically one of progress when only averages are considered. All aggregate areas and provinces advanced in terms of bed net usage (the health proxy indicator), primary school enrolment, and access to information. National use of bed nets increased fivefold to 40.1 per cent in 2013 by which time they were used nearly equally in

\footnotetext{
${ }^{1}$ Nanivazo and Mahrt (2016, forthcoming) also define a set of indicators for children aged 0-5 that includes an indicator of malnutrition.

${ }^{2}$ The Bristol health indicator is defined in terms of immunizations. Due to the limited sample from which this data is drawn and the FOD requirement that no indicator should have missing values, we define health in terms of the use of bed nets.

${ }^{3}$ Data on the possession of mobile phones was not collected in 2001. However, given the limited usage of mobile phones in 2001, this is not likely to significantly influence the results.
} 
urban and rural areas. By 2013, more than 93 per cent of school-aged children had at least some primary school education. Though this indicator measures severe deprivation and does not provide information as to completion of primary school, rural children accessing primary school increased from 77 per cent in 2007 to 90 per cent in 2013.

Progress in attaining access to improved water, sanitation, and shelter varied. While sanitation and shelter declined for the nation, urban areas, and rural areas, water improved for the nation and rural areas but declined in urban areas. Progress in water, sanitation, and shelter outcomes within the provinces also varied.

For example, access to water nearly doubled in Maniema while sanitation declined and shelter stagnated; in Sud Kivu, access to water and sanitation dropped and then bounced back to 2007 levels while shelter steadily declined; and, Nord Kivu significantly improved in all three indicators.

\section{$4 \quad$ Results}

\subsection{Temporal FOD comparisons}

Table 2 reports FOD temporal net domination results using the six indicators described in Section 3.2. FOD comparisons are made using the original survey data and one hundred bootstrap samples; the former is referred to as the static approach. Bold values indicate domination in the static case. Bootstrap outcomes are measured as the average of domination across all bootstrap samples and are interpreted as probabilities of domination. Temporal net domination measures the probability an area's welfare improves between two years minus any probability of regression. Positive values indicate the probability of advancement, blank cells stagnation, and negative values indicate the probability of regression.

The temporal FOD comparisons do not indicate significant probabilities of improvement over time in the nation, urban areas, or rural areas. Nord Kivu is the only province with a significant probability of advancing over the full study period (58 per cent). Nord Kivu and Kasai Occidental are likely to have advanced between 2010 and 2013 with probabilities of 69 per cent and 45 per cent, respectively. Only the province of Orientale exhibited advancement in the static case between 2007 and 2010, though probabilities of advancement are relatively low in the bootstrap (33 per cent). Each of the abovementioned provinces improves on average in every indicator over the relevant timeframe. In contrast, Bas-Congo improves in each indicator between 2010 and 2013 but the static FOD case does not provide evidence of welfare gains. Bas-Congo illustrates that advancing in every indicator on average does not assure FOD advancement. A failure to achieve net temporal FOD dominance in such a case stems from an uneven distribution of gains among children. In other words, welfare gains are not broad-based.

The lack of widespread net temporal dominance can be attributed to regression and stagnation in the water, sanitation, and shelter deprivation indicators. Of the six indicators considered, health, information, and education exhibit a consistent pattern of improvement for nearly all areas. However, in each year, the direction of change in water, sanitation, and shelter welfare varies considerably. To explore the impact of each indicator on temporal results, FOD comparisons are re-evaluated excluding each indicator one by one. The results are presented in Table 3 .

Evidence of advancement in Bas-Congo, Kasai Occidental, North Kivu, and Orientale is robust even when the strongly performing indicators, health, information, and education are individually excluded. Not surprisingly, excluding sanitation and shelter leads to a significantly greater 
probability of welfare gains in both static and bootstrap FOD comparisons. Notably, excluding sanitation results in national, rural, and urban FOD advancement between 2007 and 2010, and excluding shelter results in rural advancement between 2010 and 2013. Bas-Congo appears to be quite sensitive to the distribution of gains. Though welfare gains are not registered in FOD comparisons using all six indicators, excluding education, information, shelter, sanitation, or water leads to 2013 dominating 2010 in the static sample and greater probabilities of domination in the bootstrap samples; this is particularly interesting as education and information are indicators that on average improved between 2010 and 2013.

\subsection{Spatial FOD comparisons}

Tables 4 through 6 report the results of the 2007, 2010, and 2013 spatial FOD bootstrap comparisons, with values in bold indicating domination in the static sample. Row (column) averages display the probability that an area first-order dominates (or is dominated by) other provinces. Therefore, provinces that are relatively better off have larger row and lower column averages. ${ }^{4}$

Spatial FOD comparisons result in a high degree of indeterminate outcomes. Focusing on dominance in the static case (bolded values) or on bootstrap probabilities greater than 10 per cent, nearly every dominant outcome occurs when Kinshasa, Sud Kivu, or urban areas dominate or when Kasai Occidental or rural areas are dominated. Indeterminacy in 2013 is even more extreme in that much of the dominance of Kinshasa, Sud Kivu, and urban areas falls out, particularly in the static case. The apparent failure of Kinshasa and urban areas to dominate poor provinces is counter-intuitive. For example, Kinshasa (the least poor province with a 2012 poverty rate of 37 per cent) not dominating Équateur (one of the poorest provinces with a poverty rate of 78 per cent) is quite surprising. Average welfare in each indicator (Table 1), provides insight into why this may be happening. The health indicator stands out as following a pattern distinctly different to other indicators. Specifically, in 2013, all aggregate areas and five provinces outperform Kinshasa compared to virtually no other area outperforming Kinshasa in any other indicator in any year. Once again, when welfare patterns are much different between populations, indeterminate outcomes are likely. To test the sensitivity of the results to bed net usage, FOD spatial comparisons are conducted excluding the health indicator; results are presented in Table 7. Without health, the counter-intuitive indeterminate outcomes are eliminated. This implies that the results are sensitive to choice of deprivation indicators as well as to their definitions. We further explore this sensitivity in the next section.

\subsection{Spatial rankings}

Spatial net domination provides a basis for ranking provinces and conveniently presenting a more detailed perspective on the evolution of relative wellbeing. Net domination measures the probability that an area dominates other areas minus the probability it is dominated by other areas. Area rankings and net domination scores are reported in Table 8.

It is worth noting that the difference between net domination scores is often not sufficiently large to distinguish robustly between differences in welfare outcomes and randomness introduced through bootstrapping. To avoid misinterpreting rankings, within the tables, shading and lines identify clusters with similar net domination scores. Within these clusters, ranks cannot be

\footnotetext{
${ }^{4}$ Note that bootstrap sampling introduces a degree of randomness into the results and care must be taken not to place too much importance on very small probabilities.
} 
established with confidence. Furthermore, for areas with similar scores, small changes in bootstrap probabilities may lead to disproportionately large rank changes. This sensitivity to small perturbations is a likely explanation for some of the fluctuations in rank changes among provinces.

Despite the need for caution in interpreting rankings, several conclusions can be drawn. Kinshasa and urban areas are ranked first or second throughout the six-year period. Despite high probabilities of temporal welfare advancement in Kasai Occidental, these gains were insufficient to improve its ranking. Kasai Occidental is ranked last in all years and is solidly last in 2013. Consistent with temporal results, Orientale jumps toward the top of the rankings in 2010, but these gains do not persist into 2013 (Orientale registers no temporal improvement between 2010 and 2013, see Table 2). Bandundu experiences the greatest increase in welfare relative to other areas, climbing five places, which is an improvement robust to randomness introduced via bootstrapping.

The FOD rankings appear to suggest a narrowing in the welfare gap among provinces as seen in the decline of Kinshasa's net dominance over other areas from .85 in 2007 to .38 in 2013. However, this narrowing is a result of the indeterminacy between urban areas and Kinshasa and many provinces due to the inclusion of the health indicator. Table 9 presents spatial rankings when the health indicator is excluded. Rather than a narrowing, the gap between Kinshasa and urban areas and all other areas is wider in all three years. Furthermore, rankings become extremely stable between years indicating that the health indicator drives much of the ranking variation seen in Table 8. Nonetheless, the ranking gain of Oriental between 2007 and 2010 is robust.

\section{Discussion}

This paper provides an evaluation of multidimensional welfare across provinces in the DRC from 2007 to 2013, a time period corresponding to local turmoil, restoration, reformation, and growth as well as declining rural consumption poverty. Application of the FOD approach to the 2010 MICS and the 2007 and 2013 DHS survey data, allows the analysis of the welfare of children aged 7-17 in terms of water, sanitation, shelter, health, information, and education.

Despite positive economic growth and consumption poverty trends, FOD temporal comparisons do not indicate broad-based advancement of welfare at the national, urban, or rural levels over the six-year period. This lack of multidimensional welfare advancement is partially due to inconsistent progress in the water, sanitation, and housing indicators. Nonetheless, all areas achieved significant reductions in the percentage of children deprived in bed net usage, access to information, and primary school enrolment. Only Nord Kivu exhibits convincing evidence of advancement across all indicators and over the full period.

Spatial FOD results are sensitive to the inclusion of the health indicator, defined as children not sleeping under a bed net the previous night. Our analysis demonstrates that the failure of Kinshasa and urban areas to dominate the most impoverished provinces in 2013 is likely due to an uneven distribution of gains; specifically, deprivation in health (as measured by bed net usage) is higher in Kinshasa and urban zones compared to a number of areas that are worse off in all other indicators. Given this sensitivity to the health indicator and its counter-intuitive pattern of deprivation, it is useful to consider if bed net usage is an informative indicator in spatial comparisons.

The value of the bed net indicator hinges on its ability to measure a reduction in children's exposure to malaria. Households in urban areas may opt to use bed nets less frequently than their rural counterparts if alternatives such as insecticide sprays are more widely available. Furthermore, 
households in less malaria prevalent areas, such as the city-centre of Kinshasa (Giovanfrancesco et al. 2012), may elect not to use bed nets without significantly increasing their exposure to malaria. In both scenarios, the bed net indicator is counting children as deprived who are not necessarily at greater risk of contracting malaria, and is therefore not an appropriate measure of deprivation in health and should not be included in FOD analysis. Alternatively, if alternative prevention measures and malaria prevalence are equal in rural and urban areas, then the lower bed net usage in Kinshasa and urban areas truly reflects a greater deprivation level. Unfortunately, the information required to assess the appropriateness of the health indicator is not available. Further data and research on household use of other malaria prevention strategies are needed in order to ascertain which of these scenarios holds.

\section{References}

Arndt, C., R. Distante, M.A. Hussain, L.P. Østerdal, P.L. Huong, and M. Ibraimo (2012). 'Ordinal Welfare Comparisons with Multiple Discrete Indicators: A First Order Dominance Approach and Application to Child Poverty'. World Development, 40(11): 2290-301.

Arndt, C., A. Hussain, V. Salvucci, F. Tarp, and L. Østerdal (2013). 'Advancing Small Area Estimation’. WIDER Working Paper 2013/053. Helsinki: UNU-WIDER.

Giovanfrancesco, F., H. Ntuku, S. Schmidlin, C. Lengeler, and A. Tshefu (2012). 'A Comprehensive Risk Map for Malaria in Kinshasa, Democratic Republic of Congo'. Malaria Journal, 11(1): 08. Available at: http://www.malariajournal.com/content/11/S1/O8 (accessed on 6 January 2015).

Gordon, D., S. Nandy, C. Pantazis, S. Pemberton, and P. Townsend (2003a). Child Poverty in the Developing World. Bristol: The Policy Press.

Gordon, D., S. Nandy, C. Pantazis, S. Pemberton, and P. Townsend (2003b). 'Using Multiple Indicator Cluster Survey (MICS) and Demographic and Health Survey (DHS) Data to Measure Child Poverty'. UNICEF MICS Conference, London School of Economics and University of Bath.

Ministry of Planning and Macro International (2008). Democratic Republic of Congo Demographic and Health Survey 2007. Calverton, MD: Ministry of Planning and Macro International.

Ministry of Planning and Monitoring the Implementation of the Modernity Revolution (MPSMRM), Ministry of Public Health (MSP), and ICF International (2014). Democratic Republic of Congo Demographic and Health Survey 2013-2014. Rockville, MD: MPSMRM, MSP and ICF International.

National Institute of Statistics and UNICEF (2011). Democratic Republic of Congo Multiple Indicator Cluster Survey 2010. Kinshasa: National Institute of Statistics and UNICEF.

Nanivazo. M., and K. Mahrt (2016, forthcoming). 'Growth and Poverty in the Democratic Republic of Congo: 2001 through 2013'. In C. Arndt, A. McKay, and F. Tarp (eds), Growth And Poverty in sub-Saharan Africa. Oxford: Oxford University Press.

UNDP (2014). Democratic Republic of Congo Millennium Development Goals Status Report 2012. Kinshasa: United Nations Development Programme.

World Bank (2014). World Development Indicators, available at: www.data.worldbank.org (accessed on 18 May 2014). 
Table 1: Children 7-17 not deprived, by welfare indicator (\%)

\begin{tabular}{|c|c|c|c|c|c|c|c|c|c|c|c|c|c|c|c|c|c|c|}
\hline & \multicolumn{3}{|l|}{ Water } & \multicolumn{3}{|c|}{ Sanitation } & \multicolumn{3}{|c|}{ Shelter } & \multicolumn{3}{|c|}{ Health } & \multicolumn{3}{|c|}{ Information } & \multicolumn{3}{|c|}{ Education } \\
\hline & 2007 & 2010 & 2013 & 2007 & 2010 & 2013 & 2007 & 2010 & 2013 & 2007 & 2010 & 2013 & 2007 & 2010 & 2013 & 2007 & 2010 & 2013 \\
\hline National & 42.9 & 49.7 & 49.9 & 90.7 & 87.9 & 88.4 & 19.6 & 22.8 & 19.6 & 8.1 & 20.6 & 40.9 & 52.1 & 58.4 & 64.2 & 82.4 & 87.6 & 93.2 \\
\hline Rural & 21.1 & 30.5 & 32.5 & 86.8 & 82.0 & 83.1 & 3.4 & 4.2 & 3.2 & 5.3 & 17.8 & 40.7 & 36.6 & 41.6 & 47.6 & 77.0 & 82.9 & 90.3 \\
\hline Urban & 77.0 & 78.5 & 74.6 & 96.9 & 96.7 & 95.8 & 45.0 & 50.6 & 42.8 & 12.5 & 24.9 & 41.2 & 76.5 & 83.7 & 87.7 & 91.0 & 94.7 & 97.2 \\
\hline Bandundu & 24.3 & 19.4 & 31.1 & 87.8 & 86.1 & 85.3 & 13.1 & 4.2 & 6.4 & 5.8 & 26.2 & 59.7 & 39.0 & 39.4 & 48.4 & 77.9 & 90.4 & 94.1 \\
\hline Bas-Congo & 42.8 & 40.2 & 58.2 & 81.9 & 76.7 & 79.8 & 25.6 & 30.0 & 32.3 & 20.9 & 12.9 & 43.3 & 69.2 & 77.5 & 80.0 & 84.8 & 90.8 & 95.8 \\
\hline Équateur & 14.9 & 16.8 & 26.1 & 93.4 & 85.6 & 89.1 & 5.9 & 5.4 & 3.1 & 11.3 & 27.0 & 55.1 & 32.3 & 31.4 & 44.8 & 77.6 & 83.2 & 91.9 \\
\hline $\begin{array}{l}\text { K. } \\
\text { Occidental }\end{array}$ & 26.6 & 16.8 & 31.5 & 76.7 & 62.7 & 74.9 & 7.1 & 3.8 & 9.6 & 2.6 & 5.7 & 20.9 & 47.7 & 38.5 & 53.3 & 78.9 & 82.9 & 92.3 \\
\hline K. Oriental & 46.6 & 46.9 & 41.3 & 93.1 & 84.8 & 80.1 & 15.0 & 16.6 & 15.2 & 2.3 & 3.2 & 29.5 & 58.4 & 55.9 & 64.4 & 86.2 & 90.8 & 95.9 \\
\hline Katanga & 55.1 & 60.3 & 53.8 & 86.1 & 84.7 & 85.4 & 24.0 & 15.5 & 25.3 & 12.3 & 12.6 & 48.9 & 51.4 & 56.7 & 70.0 & 81.7 & 80.7 & 93.3 \\
\hline Kinshasa & 91.2 & 86.8 & 93.2 & 98.8 & 98.1 & 98.1 & 71.2 & 79.6 & 72.3 & 15.5 & 31.4 & 37.1 & 93.6 & 95.1 & 98.5 & 96.6 & 96.5 & 96.7 \\
\hline Maniema & 26.9 & 32.8 & 51.8 & 92.5 & 90.7 & 89.6 & 5.7 & 4.5 & 5.3 & 6.9 & 40.7 & 27.9 & 56.4 & 56.1 & 64.6 & 84.6 & 91.1 & 93.6 \\
\hline N. Kivu & 71.7 & 58.8 & 81.2 & 93.1 & 94.1 & 97.3 & 13.5 & 16.3 & 24.7 & 1.5 & 15.8 & 30.7 & 54.9 & 60.8 & 70.2 & 76.3 & 84.5 & 88.8 \\
\hline Orientale & 34.4 & 58.3 & 41.3 & 95.6 & 97.0 & 94.2 & 5.6 & 8.2 & 11.2 & 5.0 & 34.0 & 28.4 & 37.7 & 52.9 & 64.4 & 79.4 & 88.7 & 92.0 \\
\hline S. Kivu & 63.9 & 54.8 & 65.5 & 95.0 & 88.9 & 95.5 & 26.5 & 23.5 & 19.2 & 8.3 & 17.7 & 39.3 & 58.5 & 60.0 & 72.1 & 83.8 & 84.6 & 90.9 \\
\hline
\end{tabular}

Source: Authors' calculations based on DHS and MICS data (Ministry of Planning and Macro International Inc. (2008); National Institute of Statistics and UNICEF (2011); Ministry of Planning et al. (2014)). 
Table 2: Temporal net FOD comparisons (bootstrap probabilities)

\begin{tabular}{llll}
\hline & \multicolumn{3}{l}{ Children 7-17 } \\
\hline & FO10 & 2013 & 2013 \\
& 2007 & FOD & FOD \\
\cline { 2 - 4 } National & 0.01 & & 0.01 \\
Rural & 0.01 & 0.02 & 0.06 \\
Urban & 0.06 & 0.01 & \\
\hline Bandundu & 0.08 & 0.08 & 0.20 \\
Bas-Congo & & 0.19 & 0.18 \\
Équateur & & 0.01 & 0.01 \\
K. Occidental & & 0.14 & $\mathbf{0 . 6 9}$ \\
K. Oriental & & & 0.05 \\
Katanga & 0.01 & 0.14 & 0.13 \\
Kinshasa & 0.01 & 0.03 & \\
Maniema & 0.01 & 0.10 & \\
N. Kivu & 0.04 & $\mathbf{0 . 5 8}$ & $\mathbf{0 . 4 5}$ \\
Orientale & $\mathbf{0 . 3 3}$ & 0.06 & \\
S. Kivu & & & 0.15 \\
\hline
\end{tabular}

Note: Figures in bold indicate domination in FOD comparisons using the static sample.

Source: Authors' calculations based on DHS and MICS data (Ministry of Planning and Macro International Inc. (2008); National Institute of Statistics and UNICEF (2011); Ministry of Planning et al. (2014)). 
Table 3: Temporal net FOD comparisons individually excluding each indicator

\begin{tabular}{|c|c|c|c|c|c|c|c|c|c|c|c|c|c|c|c|c|c|c|}
\hline & \multicolumn{3}{|c|}{ No water } & \multicolumn{3}{|c|}{ No sanitation } & \multicolumn{3}{|c|}{ No shelter } & \multicolumn{3}{|c|}{ No health } & \multicolumn{3}{|c|}{ No information } & \multicolumn{3}{|c|}{ No education } \\
\hline & $\begin{array}{l}2010 \\
\text { FOD } \\
2007\end{array}$ & $\begin{array}{l}2013 \\
\text { FOD } \\
2007\end{array}$ & $\begin{array}{l}2013 \\
\text { FOD } \\
2010\end{array}$ & $\begin{array}{l}2010 \\
\text { FOD } \\
2007\end{array}$ & $\begin{array}{l}2013 \\
\text { FOD } \\
2007\end{array}$ & $\begin{array}{l}2013 \\
\text { FOD } \\
2010\end{array}$ & $\begin{array}{l}2010 \\
\text { FOD } \\
2007\end{array}$ & $\begin{array}{l}2013 \\
\text { FOD } \\
2007\end{array}$ & $\begin{array}{l}2013 \\
\text { FOD } \\
2010\end{array}$ & $\begin{array}{l}2010 \\
\text { FOD } \\
2007\end{array}$ & $\begin{array}{l}2013 \\
\text { FOD } \\
2007\end{array}$ & $\begin{array}{l}2013 \\
\text { FOD } \\
2010\end{array}$ & $\begin{array}{l}2010 \\
\text { FOD } \\
2007\end{array}$ & $\begin{array}{l}2013 \\
\text { FOD } \\
2007\end{array}$ & $\begin{array}{l}2013 \\
\text { FOD } \\
2010\end{array}$ & $\begin{array}{l}2010 \\
\text { FOD } \\
2007\end{array}$ & $\begin{array}{l}2013 \\
\text { FOD } \\
2007\end{array}$ & $\begin{array}{l}2013 \\
\text { FOD } \\
2010\end{array}$ \\
\hline National & 0.01 & 0.04 & 0.02 & 0.82 & 0.39 & 0.03 & 0.01 & 0.07 & 0.39 & 0.01 & 0.02 & 0.01 & 0.01 & 0.02 & 0.01 & 0.01 & 0.02 & 0.01 \\
\hline Rural & 0.01 & 0.03 & 0.17 & 0.64 & 0.36 & 0.15 & 0.01 & 0.08 & 0.56 & 0.01 & 0.02 & 0.12 & 0.01 & 0.02 & 0.13 & 0.02 & 0.02 & 0.13 \\
\hline Urban & 0.31 & 0.04 & & 0.56 & 0.06 & & 0.05 & 0.02 & & 0.02 & 0.01 & & 0.07 & 0.01 & & 0.10 & 0.02 & \\
\hline Bandundu & 0.03 & 0.09 & 0.24 & 0.08 & 0.24 & 0.66 & 0.06 & 0.20 & 0.37 & 0.03 & 0.09 & 0.21 & 0.03 & 0.09 & 0.24 & 0.03 & 0.09 & 0.22 \\
\hline Bas-Congo & 0.01 & 0.34 & 0.22 & 0.01 & 0.64 & 0.39 & & 0.29 & 0.23 & 0.04 & 0.23 & 0.19 & 0.02 & 0.27 & 0.33 & & 0.23 & 0.28 \\
\hline Équateur & & 0.02 & 0.01 & 0.06 & 0.10 & 0.01 & 0.01 & 0.15 & 0.63 & 0.01 & 0.02 & 0.01 & & 0.02 & 0.01 & & 0.02 & 0.01 \\
\hline K. Occidental & & 0.20 & 0.81 & & 0.39 & 0.79 & & 0.21 & 0.94 & -0.09 & 0.17 & 0.71 & & 0.19 & 0.71 & & 0.17 & 0.74 \\
\hline K. Oriental & & 0.01 & 0.09 & 0.02 & 0.15 & 0.11 & & 0.01 & 0.08 & & 0.01 & 0.02 & & 0.01 & 0.03 & -0.01 & 0.01 & 0.02 \\
\hline Katanga & $\overline{0} .03$ & 0.28 & 0.44 & 0.01 & 0.32 & 0.19 & & 0.13 & 0.12 & -0.01 & 0.12 & 0.12 & -0.06 & 0.13 & 0.13 & & 0.13 & 0.12 \\
\hline Kinshasa & 0.02 & 0.07 & & 0.03 & 0.08 & & 0.02 & 0.14 & & 0.02 & 0.05 & & 0.02 & 0.10 & & 0.03 & 0.15 & \\
\hline Maniema & 0.03 & 0.16 & & 0.13 & 0.28 & & 0.13 & 0.26 & & 0.04 & 0.10 & 0.08 & 0.06 & 0.10 & & 0.05 & 0.10 & \\
\hline N. Kivu & 0.36 & 0.80 & 0.46 & 0.06 & 0.68 & 0.51 & 0.06 & 0.71 & 0.76 & 0.05 & 0.63 & 0.68 & 0.05 & 0.63 & 0.51 & 0.05 & 0.62 & 0.53 \\
\hline Orientale & 0.23 & 0.09 & 0.03 & 0.59 & 0.62 & 0.02 & 0.31 & 0.10 & 0.01 & 0.20 & 0.07 & 0.01 & 0.28 & 0.07 & & 0.31 & 0.11 & 0.01 \\
\hline S. Kivu & & 0.07 & 0.21 & 0.05 & 0.05 & 0.10 & & 0.10 & 0.67 & -0.13 & 0.01 & 0.12 & & 0.01 & 0.11 & & 0.01 & 0.11 \\
\hline
\end{tabular}

Note: Figures in bold indicate domination in FOD comparisons using the static sample.

Source: Authors' calculations based on DHS and MICS data (Ministry of Planning and Macro International Inc. (2008); National Institute of Statistics and UNICEF (2011); Ministry of Planning et al. (2014)). 
Table 4: 2007 Bootstrap spatial FOD comparisons (probabilities)

\begin{tabular}{|c|c|c|c|c|c|c|c|c|c|c|c|c|c|c|c|}
\hline Areas/provinces & $\underset{\Sigma}{\mathbb{z}}$ & $\begin{array}{l}\stackrel{\Upsilon}{\supset} \\
\\
\end{array}$ & 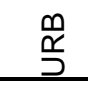 & 只 & $\begin{array}{l}\text { O } \\
\text { O্ }\end{array}$ & $\stackrel{\dddot{x}}{\underline{w}}$ & $\begin{array}{l}0 \\
\text { O } \\
\underline{1}\end{array}$ & $\begin{array}{l}\llcorner \\
\underline{0} \\
\end{array}$ & $\begin{array}{l}0 \\
\underline{E} \\
\underline{\underline{n}}\end{array}$ & $\begin{array}{l}\mathscr{D} \\
\mathscr{D} \\
\underline{1}\end{array}$ & $\sum_{\Sigma}$ & $\frac{z}{z}$ & $\begin{array}{l}\text { 上 } \\
\text { o } \\
\end{array}$ & $\underset{\omega}{\vec{x}}$ & 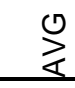 \\
\hline National (NAT) & & 1 & & 0.30 & & & 0.61 & & & & & & & & 0.15 \\
\hline Rural (RUR) & & & & & & & & & & & & & & & 0.00 \\
\hline Urban (URB) & 1 & 1 & & 0.98 & 0.01 & 0.63 & 1 & 0.85 & 0.49 & & 0.97 & 0.72 & 0.49 & 0.42 & 0.66 \\
\hline Bandundu (BDD) & & 0.18 & & & & & 0.03 & & & & & & 0.01 & & 0.02 \\
\hline Bas-Congo (BCO) & & 0.10 & & 0.04 & & & 0.67 & & 0.01 & & & & & & 0.06 \\
\hline Équateur (ETR) & & & & & & & & & & & & & & & 0.00 \\
\hline K. Occidental (KOC) & & & & & & & & & & & & & & & 0.00 \\
\hline K. Oriental (KOT) & & & & 0.04 & & & 0.19 & & & & & & & & 0.02 \\
\hline Katanga (KTG) & & 0.11 & & 0.08 & & & 0.27 & & & & & 0.01 & & & 0.04 \\
\hline Kinshasa (KSS) & 1 & 1 & 0.51 & 1 & 0.12 & 0.84 & 1 & 1 & 0.82 & & 1 & 0.98 & 0.91 & 0.83 & 0.85 \\
\hline Maniema (MNM) & & 0.20 & & 0.08 & & & 0.05 & & & & & & & & 0.03 \\
\hline N. Kivu (NKV) & & 0.01 & & 0.03 & & & 0.06 & & & & & & & & 0.01 \\
\hline Orientale (ORT) & & 0.09 & & 0.03 & & 0.01 & & & & & & & & & 0.01 \\
\hline S. Kivu (SKV) & 0.26 & 0.92 & & 0.47 & & 0.20 & 0.81 & 0.02 & 0.05 & & 0.08 & 0.14 & 0.12 & & 0.24 \\
\hline Average & 0.17 & 0.35 & 0.04 & 0.23 & 0.01 & 0.13 & 0.36 & 0.14 & 0.11 & 0.00 & 0.16 & 0.14 & 0.12 & 0.10 & 0.15 \\
\hline
\end{tabular}

Note: Figures in bold indicate domination in FOD comparisons using the static sample. A ' 1 ' in the bootstrap FOD comparisons indicates that the row (column) province dominates (is dominated by) the column provinces 100 per cent of the time. An empty cell indicates that the FOD comparison of the row and column provinces is always indeterminate

Source: Authors' calculations based on DHS and MICS data (Ministry of Planning and Macro International Inc. (2008); National Institute of Statistics and UNICEF (2011); Ministry of Planning et al. (2014)). 
Table 5: 2010 Bootstrap spatial FOD comparisons (probabilities)

\begin{tabular}{|c|c|c|c|c|c|c|c|c|c|c|c|c|c|c|c|}
\hline Areas/provinces & NAT & RUR & URB & $\mathrm{BDD}$ & $\mathrm{BCO}$ & ETR & $\mathrm{KOC}$ & KOT & KTG & KSS & MNM & NKV & ORT & SKV & Average \\
\hline National (NAT) & & 1 & & & & & 0.99 & 0.01 & 0.03 & & & & & 0.02 & 0.16 \\
\hline Rural (RUR) & & & & & & & 0.18 & & & & & & & & 0.01 \\
\hline Urban (URB) & 1 & 1 & & 0.42 & 0.66 & 0.41 & 1 & 1 & 0.99 & & & 0.93 & & 0.99 & 0.65 \\
\hline Bandundu (BDD) & & & & & & 0.02 & 0.21 & & & & & & & & 0.02 \\
\hline Bas-Congo (BCO) & & 0.01 & & & & & 0.99 & & & & & & & & 0.08 \\
\hline Équateur (ETR) & & & & & & & 0.01 & & & & & & & & 0.00 \\
\hline K. Occidental (KOC) & & & & & & & & & & & & & & & 0.00 \\
\hline K. Oriental (KOT) & & & & & & & & & & & & & & & 0.00 \\
\hline Katanga (KTG) & & 0.01 & & & & & 0.30 & & & & & & & & 0.02 \\
\hline Kinshasa (KSS) & 1 & 1 & 0.71 & 0.83 & 1 & 0.88 & 1 & 1 & 1 & & 0.05 & 0.98 & 0.32 & 1.00 & 0.83 \\
\hline Maniema (MNM) & & 0.31 & & 0.09 & & 0.10 & 0.47 & & & & & & & & 0.07 \\
\hline N. Kivu (NKV) & & 0.26 & & & & 0.01 & 0.77 & & 0.03 & & & & & 0.06 & 0.09 \\
\hline Orientale (ORT) & & 0.90 & & 0.17 & & 0.71 & 0.84 & & & & & & & 0.01 & 0.20 \\
\hline S. Kivu (SKV) & & 0.28 & & & & & 0.71 & & 0.14 & & & & & & 0.09 \\
\hline Average & 0.15 & 0.37 & 0.05 & 0.12 & 0.13 & 0.16 & 0.57 & 0.15 & 0.17 & 0.00 & 0.00 & 0.15 & 0.02 & 0.16 & 0.16 \\
\hline
\end{tabular}

Note: Figures in bold indicate domination in FOD comparisons using the static sample. A ' 1 ' in the bootstrap FOD comparisons indicates that the row (column) province dominates (is dominated by) the column provinces 100 per cent of the time. An empty cell indicates that the FOD comparison of the row and column provinces is always indeterminate.

Source: Authors' calculations based on DHS and MICS data (Ministry of Planning and Macro International Inc. (2008); National Institute of Statistics and UNICEF (2011); Ministry of Planning et al. (2014)). 
Table 6: 2013 Bootstrap spatial FOD comparisons (probabilities)

\begin{tabular}{|c|c|c|c|c|c|c|c|c|c|c|c|c|c|c|c|}
\hline Areas/provinces & NAT & RUR & URB & BDD & $\mathrm{BCO}$ & ETR & $\mathrm{KOC}$ & KOT & KTG & KSS & MNM & NKV & ORT & SKV & Average \\
\hline National (NAT) & & 0.66 & & & & & 0.78 & & & & & & & & 0.11 \\
\hline Rural (RUR) & & & & & & & & & & & & & & & 0.00 \\
\hline Urban (URB) & 0.66 & 0.66 & & & 0.13 & & 1 & 0.99 & 0.01 & & 0.95 & & 0.86 & 0.03 & 0.41 \\
\hline Bandundu (BDD) & & 0.04 & & & & & 0.04 & & & & & & & & 0.01 \\
\hline Bas-Congo (BCO) & & 0.09 & & & & & 0.78 & 0.06 & & & 0.03 & & & & 0.07 \\
\hline Équateur (ETR) & & & & & & & & & & & & & & & 0.00 \\
\hline K. Occidental (KOC) & & & & & & & & & & & & & & & 0.00 \\
\hline K. Oriental (KOT) & & & & & & & 0.57 & & & & & & & & 0.04 \\
\hline Katanga (KTG) & & 0.12 & & & & & 0.54 & & & & 0.01 & & & & 0.05 \\
\hline Kinshasa (KSS) & 0.19 & 0.22 & 0.01 & & 0.11 & & 1 & 0.82 & 0.02 & & 0.90 & 0.49 & 0.94 & 0.27 & 0.38 \\
\hline Maniema (MNM) & & & & & & & 0.11 & & & & & & & & 0.01 \\
\hline N. Kivu (NKV) & & 0.02 & & & & & 0.04 & & & & 0.01 & & 0.02 & & 0.01 \\
\hline Orientale (ORT) & & & & & & & 0.21 & & & & & & & & 0.02 \\
\hline S. Kivu (SKV) & 0.03 & 0.28 & & & & & 0.25 & & 0.01 & & 0.06 & 0.01 & 0.10 & & 0.06 \\
\hline Average & 0.07 & 0.16 & 0.00 & 0.00 & 0.02 & 0.00 & 0.41 & 0.14 & 0.00 & 0.00 & 0.15 & 0.04 & 0.15 & 0.02 & 0.08 \\
\hline
\end{tabular}

Note: Figures in bold indicate domination in FOD comparisons using the static sample. A ' 1 ' in the bootstrap FOD comparisons indicates that the row (column) province dominates (is dominated by) the column provinces 100 per cent of the time. An empty cell indicates that the FOD comparison of the row and column provinces is always indeterminate.

Source: Authors' calculations based on DHS and MICS data (Ministry of Planning and Macro International Inc. (2008); National Institute of Statistics and UNICEF (2011); Ministry of Planning et al. (2014)) 
Table 7: 2013 Bootstrap spatial FOD comparisons excluding health (probabilities)

\begin{tabular}{|c|c|c|c|c|c|c|c|c|c|c|c|c|c|c|c|}
\hline Areas/provinces & NAT & RUR & URB & $\mathrm{BDD}$ & $\mathrm{BCO}$ & ETR & $\mathrm{KOC}$ & KOT & KTG & KSS & MNM & NKV & ORT & SKV & $\mathrm{AVG}$ \\
\hline National (NAT) & & 1 & & 0.08 & & 0.06 & 0.70 & & 0.02 & & & & & & 0.14 \\
\hline Rural (RUR) & & & & & & & & & & & & & & & 0.00 \\
\hline Urban (URB) & 1 & 1 & & 1 & 0.87 & 0.99 & 1 & 0.96 & 1 & & 0.96 & 0.01 & 0.85 & 0.04 & 0.74 \\
\hline Bandundu (BDD) & & 0.09 & & & & 0.01 & 0.04 & & & & & & & & 0.01 \\
\hline Bas-Congo (BCO) & 0.01 & 0.37 & & 0.18 & & 0.03 & 0.76 & 0.09 & 0.09 & & 0.02 & & & & 0.12 \\
\hline Équateur (ETR) & & & & & & & & & & & & & & & 0.00 \\
\hline K. Occidental (KOC) & & 0.01 & & & & & & & & & & & & & 0.00 \\
\hline K. Oriental (KOT) & & 0.06 & & 0.04 & & & 0.59 & & & & & & & & 0.05 \\
\hline Katanga (KTG) & & 0.21 & & 0.04 & & & 0.50 & & & & & & & & 0.06 \\
\hline Kinshasa (KSS) & 1 & 1 & 0.18 & 0.99 & 0.89 & 0.99 & 1 & 0.73 & 1 & & 0.98 & 0.72 & 0.99 & 0.76 & 0.86 \\
\hline Maniema (MNM) & & 0.49 & & 0.04 & & 0.16 & 0.15 & & & & & & & & 0.06 \\
\hline N. Kivu (NKV) & & 0.23 & & & & 0.05 & 0.05 & & 0.02 & & & & 0.04 & 0.01 & 0.03 \\
\hline Orientale (ORT) & & 0.81 & & 0.05 & & 0.23 & 0.29 & & & & & & & & 0.11 \\
\hline S. Kivu (SKV) & 0.07 & 0.53 & & 0.08 & & 0.33 & 0.23 & & 0.05 & & 0.07 & & 0.12 & & 0.11 \\
\hline Average & 0.16 & 0.45 & 0.01 & 0.19 & 0.14 & 0.22 & 0.41 & 0.14 & 0.17 & 0.00 & 0.16 & 0.06 & 0.15 & 0.06 & 0.16 \\
\hline
\end{tabular}

Note: Figures in bold indicate domination in FOD comparisons using the static sample. A ' 1 ' in the bootstrap FOD comparisons indicates that the row (column) province dominates (is dominated by) the column provinces 100 per cent of the time. An empty cell indicates that the FOD comparison of the row and column provinces is always indeterminate.

Source: Authors' calculations based on DHS and MICS data (Ministry of Planning and Macro International Inc. (2008); National Institute of Statistics and UNICEF (2011); Ministry of Planning et al. (2014)). 
Table 8: Area rankings by probability of net domination

\begin{tabular}{|c|c|c|c|c|c|c|}
\hline \multirow{2}{*}{$\begin{array}{l}2007 \\
\text { Area } \\
\end{array}$} & \multirow[b]{2}{*}{$\begin{array}{l}\text { Net } \\
\text { Dom. }\end{array}$} & \multicolumn{2}{|l|}{2010} & \multicolumn{2}{|l|}{2013} & \multirow{2}{*}{$\begin{array}{l}\text { 2007-2013 } \\
\text { Rank } \\
\text { change }\end{array}$} \\
\hline & & Area & $\begin{array}{l}\text { Net } \\
\text { Dom. }\end{array}$ & Area & $\begin{array}{l}\text { Net } \\
\text { Dom. }\end{array}$ & \\
\hline Kinshasa (KSS) & 0.85 & KSS & 0.83 & URB & 0.41 & -1 \\
\hline Urban (URB) & 0.62 & URB & 0.59 & KSS & 0.38 & 1 \\
\hline Sud Kivu (SKV) & 0.14 & ORT & 0.18 & $\mathrm{BCO}$ & 0.06 & -1 \\
\hline Bas-Congo (BCO) & 0.05 & MNM & 0.07 & KTG & 0.05 & -2 \\
\hline National (NAT) & -0.03 & NAT & 0.00 & NAT & 0.04 & 0 \\
\hline Katanga (KTG) & -0.07 & $\mathrm{BCO}$ & -0.05 & SKV & 0.03 & 3 \\
\hline Orientale (ORT) & -0.11 & NKV & -0.06 & BDD & 0.01 & -5 \\
\hline Kasai Oriental (KOT) & -0.13 & SKV & -0.07 & ETR & 0.00 & -1 \\
\hline Équateur (ETR) & -0.13 & BDD & -0.10 & NKV & -0.03 & -2 \\
\hline Maniema (MNM) & -0.13 & KTG & -0.14 & KOT & -0.10 & 2 \\
\hline Nord Kivu (NKV) & -0.13 & KOT & -0.15 & ORT & -0.13 & 4 \\
\hline Bandundu (BDD) & -0.22 & ETR & -0.16 & MNM & -0.14 & 2 \\
\hline Rural (RUR) & -0.35 & RUR & -0.35 & RUR & -0.16 & 0 \\
\hline Kasai Occidental (KOC) & -0.36 & $\mathrm{KOC}$ & -0.57 & $\mathrm{KOC}$ & -0.41 & 0 \\
\hline
\end{tabular}

Note: Rankings within shaded groups are highly sensitive to small perturbations and should be interpreted with caution.

Source: Authors' calculations based on DHS and MICS data (Ministry of Planning and Macro International Inc. (2008); National Institute of Statistics and UNICEF (2011); Ministry of Planning et al. (2014)). 
Table 9: Area rankings by probability of net domination, (no health)

\begin{tabular}{|c|c|c|c|c|c|c|}
\hline 2007 & & 2010 & & 2013 & & $\begin{array}{l}2007- \\
2013\end{array}$ \\
\hline Area & $\begin{array}{l}\text { Net } \\
\text { Dom. }\end{array}$ & Area & $\begin{array}{l}\text { Net } \\
\text { Dom. }\end{array}$ & Area & $\begin{array}{l}\text { Net } \\
\text { Dom. }\end{array}$ & $\begin{array}{l}\text { Rank } \\
\text { change }\end{array}$ \\
\hline Kinshasa (KSS) & 0.95 & KSS & 0.96 & KSS & 0.86 & 0 \\
\hline Urban (URB) & 0.74 & URB & 0.80 & URB & 0.73 & 0 \\
\hline Sud Kivu (SKV) & 0.23 & ORT & 0.11 & SKV & 0.05 & 0 \\
\hline Kasai Oriental (KOT) & 0.07 & NAT & 0.04 & $\mathrm{BCO}$ & -0.02 & -4 \\
\hline National (NAT) & -0.03 & NKV & 0.04 & NAT & -0.02 & 0 \\
\hline Nord Kivu (NKV) & -0.05 & KOT & 0.00 & NKV & -0.03 & 0 \\
\hline Orientale (ORT) & -0.06 & SKV & -0.01 & ORT & -0.05 & 0 \\
\hline Bas-Congo (BCO) & -0.09 & $\mathrm{BCO}$ & -0.05 & KOT & -0.08 & 4 \\
\hline Maniema (MNM) & -0.11 & MNM & -0.07 & MNM & -0.09 & 0 \\
\hline Katanga (KTG) & -0.13 & KTG & -0.15 & KTG & -0.11 & 0 \\
\hline Équateur (ETR) & -0.26 & BDD & -0.17 & BDD & -0.18 & -1 \\
\hline Bandundu (BDD) & -0.29 & ETR & -0.37 & ETR & -0.22 & 1 \\
\hline Kasai Occidental (KOC) & -0.43 & RUR & -0.48 & KOT & -0.41 & 0 \\
\hline Rural (RUR) & -0.52 & $\mathrm{KOC}$ & -0.65 & RUR & -0.45 & 0 \\
\hline
\end{tabular}

Note: Rankings within shaded groups are highly sensitive to small perturbations and should be interpreted with caution.

Source: Authors' calculations based on DHS and MICS data (Ministry of Planning and Macro International Inc. (2008); National Institute of Statistics and UNICEF (2011); Ministry of Planning et al. (2014)). 